\title{
Las razones del Dr. Mora para la separación de la Iglesia y el Estado
}

Manuel Rodriguez Lapuente.

Durante la época colonial, las relaciones entre la Iglesia y el Estado marcharon con armonía gracias a la aplicación de métodos de control de la Corona que redujeron la injerencia política del poder espiritual convirtiéndolo en un instrumento estatal. Desde el descubrimiento de América los Reyes Católicos obtuvieron del papa Alejandro VI amplias atribuciones en materia eclesiástica que después fueron ratificadas y ampliadas por el mismo papa en 1501 , y por Julio II en 1508.

Mediante estas facultades los reyes adquirieron el derecho de "presentación" al pontífice de los candidatos a obispos, lo que se tradujo en la práctica en la facultad de designarlos, favoreciendo la tranquilidad dentro del reino español. Asimismo, lograron que se les cediera el cobro de los diezmos y otras contribuciones eclesiásticas con lo cual el clero pasaba a "dependèr" económicamente de la Corona y se ejercía sobre él una rigurosa vigilancia estatal. Para tener un control todavia más estricto sobre la Iglesia en sus dominios, los monarcas se atribuyeron la facultad de revisar las sentencias de los tribunales eclesiásticos -que ellos mismos directa o indirectamente designaban- mediante el denominado "recurso de fuerza" y para impedir que escaparan a su autoridad las relaciones del clero con Roma, impusieron el "pase regio", mediante el cual revisaban o autorizaban o retenian a su criterio los documentos pontificios dirigidos a los dominios españoles. Este conjunto de atribuciones constituia lo que se denominó "Real Patronato Universal de las Indias".

Estas facultades colocaban a la Iglesia en un estado de sujeción en el aspecto político, económico y administrativo. A cambio de esa subordinación, la Iglesia y los eclésiásticos considerados individualmente, gozaban de notables privilegios. Así, la religión católica constituía la religión oficial con exclusión de cualquier otra y el Tribunal del Santo Oficio de la Inquisición se encargaba de garantizar la exclusividad. El Derecho Canónico y las autoridades eclesiásticas contaban con el poder coactivo del Estado y el clero disfrutaba del fuero o estatuto jurídico especial y de importantes concesiones y privilegios, situación que permitió a las corporaciones religiosas acumular considerables riquezas y ejercer una gran influencia ideológica. Por otro lado, los altos dignatarios eclesiásticos gozaban de una posición igual o superior a la de los más encumbrados funcionarios civiles, garantizando con ello la obediencia a la Corona.

El sistema prevaleció tanto en la Península como en sus colonias hasta los años anteriores a la proclamación de la Independencia de México debido a la influencia que empezó a adquirir el pensamiento liberal. 
La Iglesia mexicana vio en la emancipación del país del poder hispano la ocasión de librarse de la férrea tutela que éste habia ejercido sobre ella. La Junta Interdiocesana que se reunió a raíz de la independencia dictaminó que: ... por la Independencia del Imperio [mexicano] cesó el uso del Patronato que en sus iglesias se concedió por la silla apostólica de los Reyes de España como reyes de Castilla y León: Que para que lo haya en el Supremo Gobierno del Imperio sin peligro de nulidad en los actos, es necesario esperar igual concesión de la misma Santa Sede. ${ }^{1}$ Si bien deseaba la cancelación del patronato, quería el clero mantener, ante las nuevas autoridades civiles, sus fueros y privilegios, ventajas que le habia proporcionado su anterior relación dentro del Estado español.

La armonia existente entre ambas instituciones, poder civil y espiritual, se vio puesta en entredicho. Las relaciones Estado-Iglesia se convertirian en uno de los grandes problemas que enfrentarian los legisladores mexicanos al presentarse en los debates del Congreso diversas tendencias ideológicas que chocaban entre sí.

La preocupación sobre este punto hizo que se manifestaran principalmente dos corrientes de pensamiento: una que aspiraba a la secularización de la sociedad y que planteaba la estricta separación entre el orden temporal y el espiritual y una segunda postura que quería mantener para México el derecho de patronato de la Corona española. Ambas tendencias contribuirán a delinear el pensamiento de aquéllos que se nombraron liberalés y de aquéllos otros llamádos conservadores que lucharon arduamente por tratar de mantener el orden que había imperado a lo largo de la dominación española.

Dentro de los liberales se presentaban dos posiciones: para unos, el Patronato era una "regalía" de la Corona, es decir, un derecho inherente a la soberanía del monarca y, por lo mismo, al trasladarse la soberanía a la Nación mediante la Independencia, las atribuciones del Patronato pasaban automáticamente a ésta, sin necesidad de nuevas concesiones de la Santa Sede. Pero, para los más radicales, ya que la libertad religiosa era uno de los Derechos del Hombre, el Estado no debería adoptar ninguna religión y, por lo tanto, se debería establecer la más completa separación entre la Iglesia y el Estado. Esto implicaba que éste renunciara a sus derechos en materia eclesiástica y la Iglesia disfrutaría de la más completa libertad en su régimen interno, pero perdería los fueros y privilegios de los que hasta entonces había gozado.

La posición del clero, y de los llamados conservadores, y aún la de aquéllos liberales que pretendian buscar una solución mediante un acuerdo con el Vaticano, se vio obstaculizada porque éste, comprometido con la posición legitimista de las viejas monarquías absolutas de Europa, y acérrimos partidarios los propios papas de aquella época de esta forma de gobierno, no podian aprobar la sublevación de las colonias españolas en contra de su "legítimo" monarca, por lo cual se negaron a reconocer la Independencia de los Estados latinoamericanos. ${ }^{2}$

\footnotetext{
1 Mariano Cuevas, S.J., Historia de la nación mexicana, México, Talleres Tipográficos Modelo S.A., 1940.

2 México no obtuvo el reconocimiento de la Santa Sede hasta 1836 , quince años después de haberse emancipado de España.
} 
La idea de ejercer el patronato sin la anuencia de Roma se mantuvo durante algún tiempo. Todavía, por ejemplo, la Ley promulgada el 17 de diciembre 1833 por don Valentín Gómez Farías en funciones de presidente de la República, para el nombramiento de párrocos se basaba en las facultades que las Leyes de Indias concedían a los virreyes para hacer tales designaciones. Sin embargo, la opinión del Partido Liberal se fue inclinando de modo cada vez más decidido por solucionar el problema mediante la separación de la Iglesia y el Estado.

Naturalmente, los argumentos que se daban para sostener esta tesis, eran argumentos de carácter estrictamente político. Como lo eran, la necesidad de garantizar la libertad individual para abrazar cualquier creencia religiosa, la de suprimir el régimen de excepción de que gozaban algunas corporaciones -como la Iglesia y el Ejército, en primer término-para hacer posible el funcionamiento del sistema democrático y representativo que exige la libertad y la igualdad de los ciudadanos y, sobre todö, confirmar la soberania del Estado, puesta en entredicho por el poder de la Iglesia.

La divergencia de opiniones sobre la posición de la Iglesia frente al Estado vino a ocupar el centro de la polémica entre liberales y conservadores y pronto la discusión se trasladó al campo de batalla impidiendo así, junto con otros factores que no cabe analizar aquí, el pacífico y ordenado funcionamiento del sistema político establecido por la Constitución de 1824.

El Dr. José María Luis Mora, que tanta confianza había puesto en la Constitución para establecer un régimen democrático, republicano y federal que asegurase la libertad individual y la prosperidad de la nación, hubo de comprender, que la Constitución sería del todo ineficaz si antes no se realizaban profundas reformas sociales y, en primer término, la separación entre la Iglesia y el Estado, que conducía necesariamente a la secularización de la sociedad.

Mora poseia, además de un brillante talento, una especial preparación para abordar los problemas del país en general y, particularmente el de las relaciones de la Iglesia y el Estado y también una larga experiencia política.

Junto con su ordenación sacerdotal había obtenido en 1820 el doctorado en teología y posteriormente, en 1827, el título de abogado. Desde joven se dedicó asiduamente al periodismo y pronto fue reconocido como uno de los más lúcidos exponentes de las doctrinas liberales y un hábil polemista. A raíz de la Independencia fue electo para la Diputación Provincial de lo que sería después el Estado de México, en cuyo Congreso Constituyente también participó. Desde entonces mantuvo una actividad política incesante hasta que al ser expulsado del poder Gómez Farías, de quien habia sido su principal consejero y colaborador, hubo de salir en 1834 del pais al que nunca volvió.

Aunque mucho escribio sobre las relaciones entre la Iglesia y el Estado, en 1833 hizo una exposición sistemática del tema en su "Disertación sobre la naturaleza y aplicación de las rentas y bienes eclesiásticos, y sobre la autoridad a que se hallan sujetos en cuanto a su creación, aumento, subsistencia o supresión".

A diferencia de los demás pensadores liberales, que plantean esta separación como una necesidad política, para poder consoli- 
dar la soberanía del Estado, Mora, que era un esclarecido teólogo, propugna por ella en beneficio de la propia Iglesia. Es notable por lo demás, que Mora no cite nunca autores laicos.

Ya entonces el clero y los conservadores y, después, los historiadores de esa tendencia, se han negado a aceptar la distinción entre la religión, como doctrina y normas morales y del clero como organización eclesiástica con intereses temporales. De este modo, cualquier proposición de reforma o cambio en las condiciones politicas o económicas de la Iglesia, se interpretaba como un ataque en contra de la religión. Es fácil comprobar que en toda la amplísima literatura liberal no se discutieron nunca cuestiones dogmáticas o morales.

Por lo que hace al Dr. Mora, él sostiene enfáticamente que "Sin religión ni culto, no puede haber sociedad ni moral pública en ningún pueblo civilizado". Pero precisamente por eso, para mantenerla en toda su pureza es necesario purgarla de los elementos que la degradan, porque "la religión tampoco puede existir ni ser amada. cuando se pretende confundirla con los abusos de la superstición, con la ambición y codicia de los ministros del altar". 3

Por eso, ante todo, es necesario establecer una clara distinción entre lo que es esencial en la Iglesia y lo que no lo es, para evitar esa confusión que se mantenia en beneficio de las posiciones politicas del clero, porque como dice Mora "...se había hecho creer a los habitantes de México que las bases fundamentales de la religión y las pretensiones del clero eran una misma cosa" y lo que a él, como sacerdote, más le preocupa es que, "desacreditadas éstas (las pretensiones del clero) aquéllas, (las bases de la religión) no pudieran sostenerse y vinieran abajo..." Así “...esta derrota lo fue no solamente de la superstición, cosa que ciertamente habría sido un gran bien para el país, sino que trajo consigo la ruina de los principios religiosos en una gran parte de la población, mal muy grave en el orden público."

Por esto Mora establece nítidamente esa distinción y la apoya en argumentos teológicos e históricos. "La Iglesia puede considerarse bajo dos aspectos, o como cuerpo místico, o como asociación politica; bajo el primer aspecto, es la obra de Jesucristo, es eterna $\mathrm{e}$ indefectible, eternamente independiente de la potestad temporal: bajo el segundo, es la obra de los gobiernos civiles, puede ser alterada y modificada, y aún pueden ser abolidos los privilegios que debe al orden social, como los de cualquier otra comunidad politica."

Mora funda teológicamente la distinción en citas del Nuevo Testamento, comenzando por el pasaje del Evangelio en el que Cristo afirma "que su reino no era de este mundo, que no había venido a fundar un imperio civil" y agrega numerosos testimonios de los Padres de la Iglesia en favor de su tesis. Pero recurre también a la Historia para confirmarla y establece también aquí que hace necesario "distinguir las dos épocas más notables que ha tenido (la Iglesia) y se hallan bien caracterizadas en su historia; la primera antes de Constantino, y la segunda después que este príncipe hizo profesión pública de Cristianismo. En la primera sólo

\footnotetext{
${ }^{3}$ Todas las citas del Dr. Mora están tomadas de la "disertación sobre la naturaleza y aplicación de las rentas..."
} 
existia el cuerpo místico de la Iglesia; se predicaba la palabra divina, se administraban los sacramentos, se decidían las cuestiones de fe y costumbres...." Pero, "Cuando Constantino se convirtió al Cristianismo, la Iglesia apareció ya como comunidad política: entonces empezaron sus ministros a adquirir bienes, a tener un fuero exterior y jurisdicción coactiva, a disfrutar el derecho de imponer a sus súbditos ciertas penas temporales, y obligarlos por la fuerza a someterse a ellas; entonces finalmente adquirieron las comodidades, honores y distinciones civiles de que actualmente disfrutan".

La primera conclusión que se deriva lógicamente de estas bases es que la Iglesia y el Estado son dos entidades radicalmente distintas y que por lo mismo pueden vivir separadas. $Y$ no sólo eso, sino que, como antes lo ha señalado, es mejor para la Iglesia mantenerse separada del Estado, porque así evita contaminarse de los elementos políticos y de los privilegios civiles que la han desprestigiado.

Para el Dr. Mora la Iglesia, considerada exclusivamente como sociedad religiosa goza de determinados derechos que son inherentes a su misión específica, pero de ahí "...se deduce que los únicos derechos que a los ministros de la Iglesia corresponden de modo indefectible, son los que disfrutaban en la primera época en que no existia sino como cuerpo místico, y que pueden perder sin detrimento alguno de la religión los que adquirió en la segunda en clase de comunidad política..."

Lo que interesa subrayar aquí para seguir el raciocinio de Mora, es que estos últimos derechos -como por ejemplo el de propiedad o el fuero eclesiástico- no son de origen divino, como el clero pretendia, puesto que no los instituyó Jesucristo, sino Constantino, es decir, el poder civil los concedió, por lo que el poder civil tiene facultades para suprimirlos.

Sin embargo, al margen de estas consideraciones, persistía el hecho de que, no solamente durante la época colonial se había considerado a la religión católica como religión del Estado, sino que la misma Constitución de la República de 1824, establecía en su artículo 3 que "La religión de la nación mexicana es y será perpetuamente la católica, apostólica y romana. La nación la protege por leyes sabias y justas, y prohíbe el ejercicio de cualquier otra". Es indudable que, al consagrar al catolicismo como religión oficial, se daba lugar a esa confusión entre la Iglesia y el Estado puesto que el clero, en estas condiciones, cumplía una función política ya que sostenía la religión constitucional y si en este sentido podía considerarse a los eclesiásticos como funcionarios públicos -como efectivamente los consideró antes la Corona espanola-parecía explicable que gozaran de prerrogativas y derechos especiales. Lo irregular de una situación como ésta radica en que sería un cuerpo de funcionarios que gozaba de una amplia autonomia frente al Estado y dependian, en última instancia de Roma.

Desde el punto de vista exclusivamente político podía aducirse que esto constituia una grave limitación para el Estado y que, además, era contrario a las libertades individuales. Pero, como hemos visto, no es éste el enfoque adoptado por el Dr. Mora y por ello su argumentación se mantiene estrictamente en el plano teológico:

La autoridad eclesiástica, dice el padre Mora, para obtener el 
apoyo de los gobiernos a sus prerrogativas ha sostenido "por fundamento de semejantes pretensiones, que no sólo los particulares que profesan el catolicismo son súbditos de la Iglesia, sino también los gobiernos considerados como tales". "Es necesario, sin embargo -agrega-, convenir en que esta pretensión no sólo carece de apoyo en el evangelio, sino que es al mismo tiempo injusta e infundada." Porque Jesucristo "no vino a predicar su doctrina a los gobiernos sino a los hombres; ni a conquistar reinos sino almas". Tampoco solicitó el apoyo de las potestades de la tierra... "Los cristianos de los primeros siglos.... jamás se dirigieron a los gobiernos, a los emperadores ni a los reyes en demanda de auxilios que sostuviesen por la fuerza su religión."

Como lo hace con las tesis anteriores, el teólogo liberal demostrando un amplio conocimiento de la patrística invoca también en apoyo de ésta el testimonio de algunos de los escritores de los primeros siglos de la Iglesia, lo cual le permite concluir: "Tan expresos' como los anteriores hay otros muchos pasajes en las obras de estos y otros Padres, que confirman no ser los gobiernos los que deben apoyar a la Iglesia, y de consiguiente no estar en obligación de hacerlo, pues ella no reconoce sino a los particulares como sus únicos súbditos..."

La conclusión extrema a la que lo conduce la impecable lógica que ha seguido en su raciocinio es que los gobernantes, aunque en lo personal sean católicos, "...considerados como gobiernos no son súbditos de la Iglesia, ni tienen para con ella obligaciones ningunas, pues este cuerpo místico y espiritual fundado por Jesucristo, considerado como tal, no reconoce por súbditos sino a los fieles en particular, y no a los gobiernos a que ellos pertenecen".

Aunque no impugna explícitamente el artículo 3 de la Constitución, la conclusión que se deriva de estos argumentos es obvia.

La protección de la religión a la que hacia alusión la Constitución de 1824 , y de la que había gozado bajo el rẻgimen español, se traducia en múltiples ventajas para la Iglesia, pero lo que en esos momentos -en 1831 - más se debatía y más preocupaba al clero era lo relativo a los bienes de la Iglesia. Aunque mucho se ha debatido sobre su monto, todos los autores coinciden en que representaban un porcentaje muy alto de la riqueza nacional. Dentro de una economía liberal, como la que se trataba de implantar en el país, que exige la libre movilización de los factores de la producción para que puedan adecuarse con la mayor agilidad a las demandas del mercado, la "amortización" de estos bienes -principalmente las propiedades agrícolas- en manos del clero, constituian un grave obstáculo, dificultando la inserción del país al mercado mundial.

Pero también significaba un problema político. La Independencia se tradujo en una desorganización del viejo y complicado sistema fiscal español que, unida a los trastornos civiles de los últimos años, habían llevado al gobierno a la penuria. Frente a una Iglesia económicamente tan poderosa, el Estado se encontraba en una situación sumamente precaria y vulnerable.

Es por esto que el Dr. Mora, concede especial atención a este problema que, por lo demás, constituía el tema central de su estudio. Pero consecuente con el método que se ha impuesto, no aduce las razones que acabamos de exponer, sino 
que lo basa en argumentos intrínsecos a la naturaleza de la Iglesia.

Por los motivos señalados Mora se extiende en este punto más que en los anteriores y analiza y fundamenta muy pormenorizadamente cada uno de los aspectos de la cuestión. Pero aquí nos bastará con transcribir algunas de sus premisas y la conclusión a la que éstas le conducen.

Sin embargo, el polemista tiene que empezar por rebatir los argumentos de la parte contraria y, entre éstos el que mayor fuerza ostenta ante el pueblo católico, es que los bienes de la Iglesia son intocables porque pertenecen a Dios. Por lo tanto, secularizarlos, como pretende hacerlo el Partido Liberal, es un sacrilegio, es tanto como despojar a la divinidad. Resumiendo esta tesis dice "Si hubiese de creerse al clero, los bienes temporales que disfruta son de origen divino, y los posee por un derecho igual; puede adquirirlos sin autorización, sin consentimiento, y aun con positiva repugnancia de los gobiernos civiles; una vez que los ha hecho suyos, no le es lícito enajenarlos ni perderlos, y deben quedar para siempre en su poder exentos de la potestad civil en su administración e inversión".

Mora desbarata esta teoria de un solo golpe, con un argumento de evidencia: "El dinero, las tierras, sus frutos y cuanto se halla destinado al sostenimiento de las iglesias, es esencialmente material". Por lo mismo "...si son por su naturaleza temporales, jamás pueden dejar de serlo en ninguna suposición posible". Sin embargo "...de la palabra eclesiásticos, aplicada a los bienes destinados al culto, se ha querido inferir que se espiritualizaron, y de semejante transformación se desciende a su independencia de la autoridad civil y a un derecho divino para poseerlos, administrarlos y adquirirlos sin intervención ninguna del poder público". Interesa subrayar aquí cómo esta tesis se traduce en un patente menoscabo de la jurisdicción del Estado y, por ende de su soberanía, puesto que una parte de la riqueza del país -que además, en este caso, por su cuantía, ejercía una influencia determinante en la vida del país- no se regía por la legislación nacional ni estaba sujeta a las autoridades civiles, administrativas o judiciales.

Puede observarse aquí con toda claridad cómo semejante situación era incompatible con el proceso de formación del Estado nacional en el que estaba empeñado el país después de su emancipación.

Fiel al método que se ha impuesto, el Dr. Mora acude primero a la fuente original del cristianismo que es el Evangelio y deduce la refutación de las tesis clericales del pasaje en el que Cristo, interrogado por los fariseos sobre si es lícito pagar tributo al Emperador, ordena devolver al César lo que es del César. "Es claro -comenta Mora- que Jesucristo, en una lección cuyo único objeto era distinguir las cosas temporales de las espirituales, numeró entre las primeras la moneda que representaba todos los bienes por su naturaleza materiales..." "Jesucristo repitió constantemente que su reino no era de este mundo, y de consiguiente que no pendia su subsistencia de las riquezas, que son la base de los gobiernos temporales." "En fin -concluye- se necesita no tener el conocimiento más superficial del Evangelio ni del carácter de la divina religión que instituyó Jesucristo, para asegurar que le es necesario el contar con otros bienes distintos de las oblaciones voluntarias de los fieles, en frutos o valores que 
deben consumirse inmediatamente al sustento de sus ministros."

No obstante, si bien es cierto que la Iglesia puede vivir sin poseer bienes, "...esto no quiere decir que la posesión de ellos sea contraria a su institución, como han pretendido algunos herejes... pero como no puede disfrutarlos en clase de cuerpo místico sino de comunidad política, el derecho para adquirirlos y conservarlos es esencialmente civil... y debe estar enteramente sujeto, como el de todos los cuerpos políticos, a la autoridad temporal".

En este punto se presenta en toda su gravedad el conflicto de jurisdicciones puesto que la Iglesia sostenía que sus bienes y posesiones estaban sujetas al derecho canónico. Mora resuelve este problema afirmando que, cuando este derecho se refiere a materias estrictamente civiles, y no a cuestiones relativas al régimen interno de la Iglesia, aquella "parte del derecho canónico está enteramente sujeta a la potestad civil" puesto que se trata de "...las facultades que los gobiernos temporales han acordado expresamente a la Iglesia, o permitido que las ejerza por su tácito consentimiento". Por lo tanto son "...revocables en el caso que éste (el Gobierno civil) llegare a tenerlo por conveniente". Sólo resolviendo de este modo el problema puede salvarse el principio de la soberania del Estado.

Establecidas estas bases la conclusión es insoslayable: "Si la autoridad temporal tiene algunos derechos sobre los bienes de los cuerpos políticos, y si la Iglesia es uno de éstos, no hay duda que sobre ellos puede ejercerlo, sin necesidad de ponerse de acuerdo con los pastores que por su autoridad espiritual son enteramente extraños e incompetentes en los asuntos civiles, y de consiguiente en los que corresponden a la Iglesia misma, bajo el aspecto de comunidad politica."

El mismo razonamiento es válido para todas las demás atribuciones de carácter civil que ejerce la Iglesia, tales como la coacción que le ofrece el Estado para el pago de los diezmos u otras percepciones, para obligar al cumplimiento de los votos monásticos, para la ejecución de las sentencias dictadas por tribunales eclesiásticos o funciones de carácter civil como registro de nacimientos, matrimonios y defunciones etcétera.

La unión que había existido entre la Iglesia y el Estado en el imperio español consistía en un sistema de concesiones mutuas que para ambas partes había sido ventajoso. La Iglesia había cedido al gobierno algunos derechos estrictamente eclesiásticos, como el de la designación de los obispos y el Estado le había concedido, a cambio, las atribuciones a las que el Dr. Mora hace referencia en las transcripciones que hemos hecho. Pero al consumarse la Independencia y negarse la Iglesia a reconocer al nuevo Estado aquellas facultades, éste, para afirmar su autoridad, se ve en la necesidad de proceder con reciprocidad, cancelando las facultades civiles de que disfrutaba la Iglesia. De no hacerlo asi la soberanía nacional sería ilusoria, tanto internamente, frente a la Iglesia mexicana, como frente a la Iglesia de Roma.

Pero importa insistir, para terminar, que la separación que propugna don José María Luis Mora, no implica en modo alguno la sumisión de la Iglesia en cuanto tal, es decir como "cuerpo místico" al Estado, cosa de la que lo acusaron algunos eclesiásticos. Para él la Iglesia tiene derechos y atribuciones que le son propios 
y que puede y debe ejercitar con total independencia del poder temporal como son, según el propio Mora: predicar la palabra divina, administrar los sacramentos, decidir las cuestiones de fe y costumbres, separar de la comunión de la Iglesia al hereje pertinaz y arreglar todo lo perteneciente al modo y-forma con que se debe dar culto al Ser Supremo.

Es preciso reconocer que el Partido Liberal jamás propuso que el Gobierno interviniera en estas materias y, de hecho, las Leyes de Reforma no las afectaron en lo más mínimo.

Así quedaba a salvo la soberanía del Estado y la libertad de la Iglesia. 